\title{
Ecological Traits of Formica Aquilonia Yarrow (Hymenoptera: Formicidae) in the Environmental System of the Coal Mining Region
}

\author{
Svetlana Blinova ${ }^{1,},{ }^{,}$Aleksandra Radosteva ${ }^{1}$ and Tatiana Dobrydina $^{2}$ \\ ${ }^{1}$ Kemerovo State University, Department of Ecology and Nature Management, 650000, 6 Krasnaya \\ st., Kemerovo, Russian Federation \\ ${ }^{2}$ Kemerovo State University, Department of Foreign Languages in Professional Communication, \\ 650000, 6 Krasnaya st., Kemerovo, Russian Federation
}

\begin{abstract}
The ecological traits of the settlement of ants Formica aqiulonia Yarrow were studied in areas influenced by various anthropogenic factors (recreation, coal industry, increasing road traffic). We have revealed that ants are sensitive to any effects and in the overwhelming cases disappear from the contaminated area. Anthills with a dome diameter of 0.65-0.80 appeared to be the most resistant to various anthropogenic factors. No changes in the diet of F. aquilonia have been detected in the zone of coalmine impact. On the contrary, in the areas with a high recreational impact, the proportion first and second instar larvae of the Colorado beetle is increasing, which makes it possible to consider this species as a biological defense.
\end{abstract}

\section{Introduction}

Red wood ants (Formica rufa-group) is a widespread group of Holarctic, serves as the most important component of a greater part of terrestrial ecosystems [1]. They are able to quickly mobilize a large number of foragers in the presence of available food [2], thereby suppressing the outbreak of forest pests. As it was found in the laboratory, for example, ants Formica aquilonia can change the tactics of foraging depending on the conditions, in 2-3 days reaching the maximum possible values for ideal free distribution [3].

In general, the group of red wood ants in the Palearctic conditions is the most sensitive to anthropogenic impact: there is a decrease in species richness and in the number of anthills in the area of industrial facilities [4-5, etc.]. However, in some cases, the maximum abundance is registered with moderate impact of industry [6].

Formica aquilonia are ecologically and geographically dominant species among red wood ants in the European boreal coniferous forest. It is revealed that the degree of melanization of ant workers correlates with the degree of habitat disturbance. Thus, the increase of cuticular melanisation in F. aquilonia gynes is observed, which can be used as an ecological indicator of the degree of cenosis disturbance [7-8]. In addition, the variability of colour can be judged on the settlement of ants in the postglacial period [9].

\footnotetext{
${ }^{*}$ Corresponding author: $\underline{\text { sv blinova@mail.ru }}$
} 
Often, the degradation of indigenous ecosystems contributes to the increase of ecological niches and, as a consequence, to the increase in species richness, as shown by the example of the semiarid regions of Spain [10]. The studies by Z. R. Stahlschmidt and D. Johnson [11] have shown that urban habitats are often complex in structure, allowing the prosperity of individual species of ants.

However, the studies in Switzerland have shown no dependence in the distribution of red wood ants on the size of forests and distances from the edges and, on the contrary, dependence on the structure of the forest, the abundance of conifers and climate [1]. The dependence of ambient temperature and humidity on nesting activity of red wood ants is shown on the example of Finland [12].

The study of this group in Germany revealed a high degree of correlation in the distribution of nests of red wood ants and geochemical gas anomalies: in such areas, the density of nests is about 100 times higher [13].

Thus, according to the data, there are obvious different reactions to anthropogenic impacts on Formica rufa-group, which may be due to the ecological and climatic differences of the study areas. Therefore, the aim of this work is to study the environmental traits of ants Formica aquilonia Yarrow (Hymenoptera: Formicidae) as the most common and mass species in the coal region.

\section{Materials and Methods}

The research was carried out in 1994-2018 on the territory of the Northern part of the Kuznetsk basin (Kuzbass, Russia). Various ecological parameters of ants were studied by using standard myrmecological methods [14-16]: anthills were taken into account by the route method, paving it so that it covered all plant associations of the investigated biotope and was about $2 \mathrm{~km}$ long. All the nests within the sight were recorded: usually it is a band with a coverage area of $6 \mathrm{~m}$ in each direction. The diameter of the dome and the height of the dome in the found anthills were measured on a $5-\mathrm{cm}$ scale. According to the works of V. Czechowski; A. Radchenko, V. Chekhov [16] and B. Hôlldobler, E. Wilson [17], species belonging was identified by the taken sample of workers from the nest of 20 individuals.

The state of anthills was assessed according to the work of A. A. Zakharov, R. A. Zakharov [18].

The following parameters were used to characterize the complexes:

- the size of the complex, estimated by the number of residential anthills;

- the total number of nests (residential and auxiliary);

- the total number of columns in the complex. The number of columns in the anthill was determined by the number of outgoings from the nest first-order roads. We registered the exchange roads, the facts of formation of flowing lines, fragmentation and merging of the families, changes of nests and other manifestations of migration processes and structural changes;

- the average number of columns in the anthill for the complex;

- the dimensional structure of the complex (the distribution of nests in size classes with the class interval on the diameter of the dome $20 \mathrm{~cm}$ ). All the nests were divided into classes depending on the diameter of the dome:

I size class is with the dome diameter $<0.4 \mathrm{~m}$;

II size class is with the dome diameter $=0.45-0.60 \mathrm{~m}$;

III size class is with the dome diameter $=0.65-0.80 \mathrm{~m}$;

IV size class is with the dome diameter $=0.85-1.00 \mathrm{~m}$;

$\mathrm{V}$ size class is with the dome diameter $=1.05-1.20 \mathrm{~m}$;

VI class size is with the dome diameter $=1.25-1.40 \mathrm{~m}$; 
VII class size is with the dome diameter $>$ of $1.45 \mathrm{~m}$;

- the average diameter of the dome of a residential anthill in the complex.

Anthill condition categories.

According to their state, permanent anthills are divided into 3 categories [18]: active (growing and which stopped in the growth - stabilized), weakened and degraded. The categories of the anthill condition are assessed on the following grounds:

Active growing anthills are anthills with stable growth during the three preceding years. The dome of the nest is conical, made of fresh building material. The overgrowth of the nest with grass is weak (not more than one third of the height). There is a developed system of foraging roads with branches of the second and third orders. The other signs also indicate the active state of the nest and its population.

Active stabilized anthills have the same external characteristics of the nest, but they stopped in growth.

The weakened ones are anthills that have been shrinking in size for at least the last three years, and which are characterized by the spherical dome, composed mainly of old nesting material and exuding musty odor. Such nests usually quickly begin to overgrow with grass. The number of forages on the roads and the fodder area is decreasing. The size of the forage area is gradually decreasing too. The use of auxiliary nests and regular exchanges of individuals with the other anthills are stopped. All these features reflect the General depopulation of the anthill.

Degraded (dilapidated) nests have spherical or flattened dome with a ragged surface. Nesting material is old, darkened, and with a strong musty odor. The nest can be completely overgrown with grass. The family loses control of most of the protected area, although it preserves the number of previously available columns up to a certain limit. As a rule, such anthills fall out of the General system of intergenerational connections in the complex and are included in it only as a passive part or after fragmentation.

General characteristics of anthills complexes.

The following categories of anthill complexes were distinguished: the stages of growth, stabilization, depopulation, degradation and complete decay.

To assess the impact of the coalmine and the increased recreation on anthills, we conducted a qualitative and quantitative enumeration of ants' prey and their potential prey (biocenotic test). To do this, before the start of the study, the observed area was prepared: at a distance of $1 \mathrm{~m}$ from the foot of the anthill, we removed the branches, mowed the grass, and drew a control line with a white thread. Then we left the anthill for a day alone to let the ants adjust to the new environment.

We monitored ants' daily foraging activity at the beginning of each hour during $10 \mathrm{~min}$ for all feed paths from 9 a.m. to 9 p.m. At the same time, we registered the number of ants crossing the control line towards the nest and carrying the prey.

Simultaneously, the systematic position of the prey caught by the ants (up to the group, class) was recorded.

The organic remains - bird droppings, separate fragments of insects, brought by the ants - were included in a separate systematic group.

On the scene of the study, we collected the biocenotic sample: to study chortobionts we used the method of mowing with an entomological net in 10 series, 10 strokes in a series; to collect dendrobionts we laid a white cloth under the canopy of a tree or a bush. We shook the branches intensively several times, folded the cloth roll, and carefully unfolding the cloth, collected invertebrates in the stain. The collection of herpetobionts was carried out by soil sampling with the usage of a frame $25 \times 25 \mathrm{~cm}$.

In an industrial coal region, it is difficult to single out the areas with only one type of impact, so when presenting and analyzing the data, we are speaking about the predominant 
types of impact. Thus, we observed the impact of the recreational press on the example of a large settlement of ants in $40 \mathrm{~km}$ north of Kemerovo.

Totally, about 1000 hours of field observations were carried out to identify ecological features of $\mathrm{F}$. aquilonia ants.

All the obtained material was processed in Microsoft Excel 2016 and Statistica V. 6.0. For numerical values, the mean values for the study \pm standard deviation are given.

\section{Results and discussion}

The ants of F. aquilonia are boreo-Transpalaearctic species [16]. On the territory of the Kuznetsk-Salair mountain region, F. aquilonia, the most massive species of red wood ants, inhabits various types of forests, preferring coniferous ones (taiga). In the mountains, it occurs up to the upper forest limit (1600-1700 m above sea level). Single anthills are found in high-grass meadows located in the glades of mountain taiga cenoses.

On the studied territory, F. aquilonia builds domed nests. The dome of anthills consists of plant residues of large and medium size; in the conditions of boreal forests, it consists mainly of fragments of twigs of coniferous trees. The size of the domes can reach a diameter of 30 to $300 \mathrm{~cm}$ and a height of 15 to $200 \mathrm{~cm}$.

On average, in the Kuznetsk-Salair mountain region there are 2 nests per $1 \mathrm{~km}$ of route accounting (excluding federations). In general, we revealed a direct correlation between the degree of anthropogenic impact and the height of the nest. Thus, the average height of anthills in the habitats with a weak degree of anthropogenic impact is $85 \mathrm{~cm}$; in the places with a greater anthropogenic impact, it is $35 \mathrm{~cm}$.

In general, on the territory of the studied region, F. aquilonia forms numerous clusters, ranging from 15 to 100 nests. Most of them are located far from the impact of the coal industry and represent federated complexes at the stage of stabilization. The anthills in the category of active stabilizing predominate. As a rule, all these federations are located either in specially protected areas of the region or in the interior of the boreal taiga.

\subsection{Impact of deep mines and opencast mines on Formica aquilonia}

The impact of highways (constantly increasing road traffic) and the opencast coal mine approaching was studied by the example of the F. aquilonia anthill cluster, which is a federated complex of ants, i.e. the union of several colonies that maintain kinship through exchanges of individuals.

At the beginning of the studies in 1994, there we identified 97 anthills. By the end of the study, only 45 anthills were found. At the same time, during the last 4 years of observations, we recorded an even increase in recreational and anthropogenic impact on ants. It should be emphasized that the number of abandoned nests never exceeded the absolute number 2 , which shows an adequate reaction of the ants' federation to such effects, i.e. all disappeared anthills "joined" in the existing ones.

As shown by the correlation analysis, the number of the residential anthills $(r=-0.88$ $\mathrm{p}<0.05)$ and their average diameter $(\mathrm{r}=-0.80 \mathrm{p}<0.05)$, the number of columns in the complex $(\mathrm{r}=-0.88 \mathrm{p}<0.05)$ and the average number of columns in the anthill $(\mathrm{r}=-0.88 \mathrm{p}<0.05)$ decreases significantly as the degree of anthropogenic influence increases (Fig.1). 


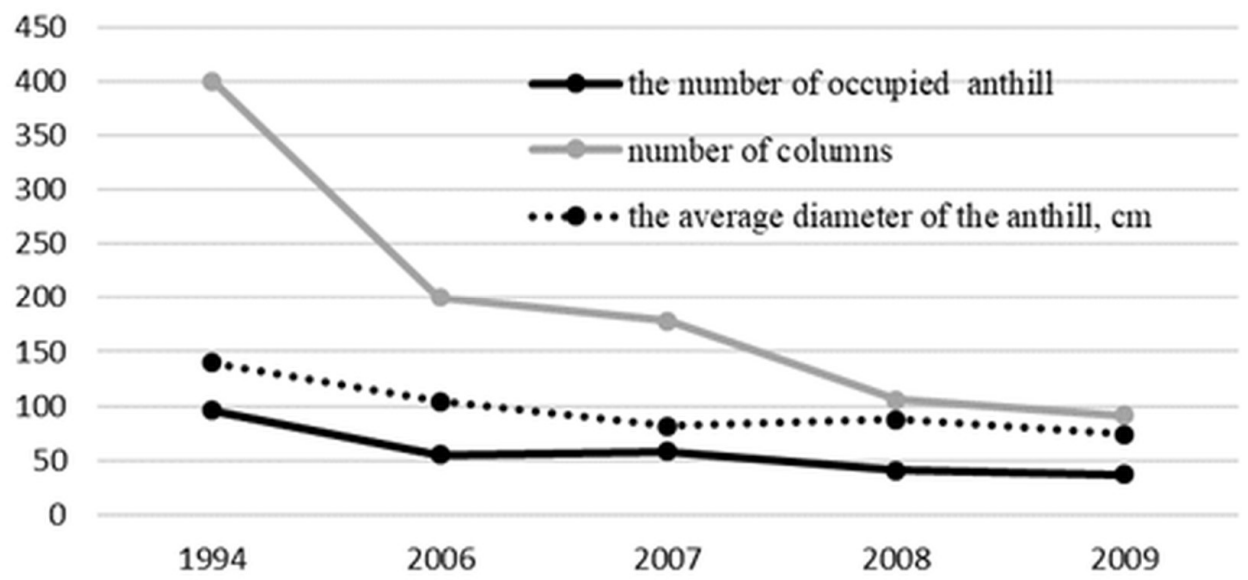

Fig. 1. Characteristics of the complex Formica aquilonia in different years of observation.

However, against the background of the overall decrease of all the parameters, the modified ratio of different size classes of nests depending on the degree of exposure appears to be very interesting (Fig. 2). It is obvious that the number of the largest and smallest nests (VII and I size classes) decreases sharply with increasing anthropogenic impact (respectively, $r=-0.95$ and $r=-0.69 p<0.05)$. At the same time, the proportion of nests with intermediate dome diameter increases (for size class III $r=-0.93 p<0.05$ ). The anthills of size class III with a dome diameter of $0.65-0.80 \mathrm{~m}$ (initially there were less than $10 \%$ such nests, by the end of the study - about $30 \%$ ) presents a significant proportion by the end of the study.

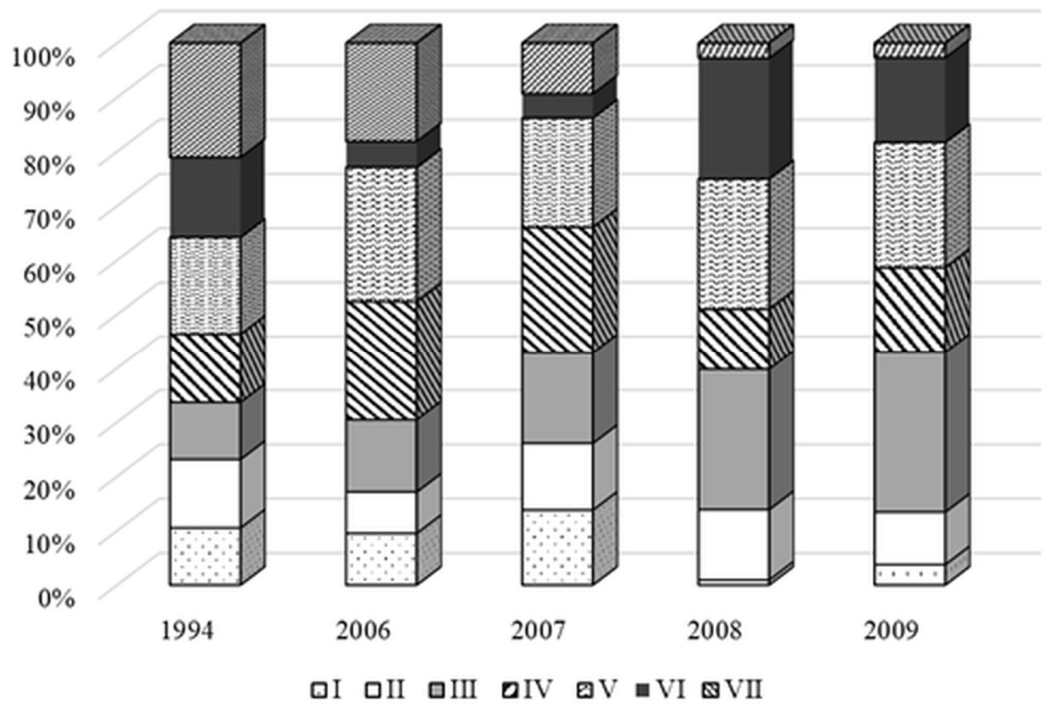

Fig. 2. Distribution of Formica aquilonia nests by size classes. The explanation of the size classes is in text.

It should be noted that we observed the abandoned anthills with an increase in the impact of the coal industry, even with the approach of the opencast mine at a distance of about $2 \mathrm{~km}$ to the nests: only one of the four model anthills located at a distance of 10-56 m from each 
other remained. At the same time, the size of this anthill slowly increases in size. We have not found any new nests or their relocation.

It is of interest that the insects of the Diptera order generally predominate in the biocenotic sample. Their share increases by $25 \%$ at the approach of the opencast mine and, as a consequence, with the increase in its impact. However, the share of Diptera in the food of ants remains almost unchanged - about $18.5 \%$.

\subsection{Recreational impact}

As we have previously shown [19] and our further studies have clarified, ants Formica aquilonia do not stand the recreational impact: first, the size of anthills sharply reduces by about $20 \%$, then there is fragmentation of individual nests and their disappearance. However, if a man violates the integrity of the nests, the process becomes clearer and faster. Therefore, for one season in 2007, we observed the disappearance of 1 anthill with the initial height of $140 \mathrm{~cm}$ and diameter of $180 \mathrm{~cm}$. By mid-summer, the nest was fragmented into 5 small anthills located on the site of the dome (along the shaft of the original nest). They had an average height of $25 \mathrm{~cm}$, a diameter of $30 \mathrm{~cm}$. By September, all anthills had disappeared. In parallel, we observed the appearance of new nests at a distance of about 50 and $100 \mathrm{~m}$. The additional studies showed that the ants took the disappeared anthill as a basis and "moved" the nest to a more favourable place - away from places with a high degree of recreational impact. The other researchers [18] indicated similar reactions, which appeared as a response to the destruction of anthills.

At the same time, a reverse process is often observed in recreational forests: smaller anthills merge with the formation of a "super-nest"; they reach a height of up to $200 \mathrm{~cm}$ and a diameter of up to $300 \mathrm{~cm}$. Close to such anthills at a distance of up to $500 \mathrm{~m}$ in diameter, we did not observe the other nests belonging to Formica s. str.

Additionally, we conducted a study of ant nutrition in the recreational area.

Model anthill is located between the garden plots under the birches (Betula pendula). It should be noted, that the anthills already located on this territory was taken into account when the garden complex was built. In the extraction of red wood ants and biocenotic sample, first and second instar larvae of the Colorado potato beetle, imago earwigs and woodlice were identified. It was in contrast to the previously described ones, taken in a relatively clean and not recreationally influenced site. These groups make up less than $1 \%$ of the total ant catch per day and occupy the same volume in the biocenotic sample. This fact allows us to speak about the possibility of using red wood ants and specifically F. aquilonia for biological protection of potato plantings from the Colorado potato beetle.

\section{Conclusion}

F. aquilonia, whose anthills that are found in various types of forests, preferably in taiga, is the most common group of red wood ants in the territory of Kuzbass. Most of the identified nests join into federated complexes at the stage of stabilization.

However, any kind of anthropogenic impact (recreation, coal industry, increasing road traffic) affects the state of anthills. We have revealed a direct correlation between any degree of anthropogenic impact and dimensional characteristics of the nest; the number of residential anthills and columns in them is reduced.

An increase in the proportion of anthills of size class III with a dome diameter of 0.650.80 has been defined as an adaptation to the increase in exposure. 
Under the influence of the coalmine, we have found no changes in the diet of F. aquilonia. On the contrary, in areas with high recreational impact, the proportion of first and second instar larvae of the Colorado potato beetle, imago earwigs, and woodlice increases, which allows us to consider this species as a biological protection of potatoes from pests.

\section{References}

1. M. L. Vandegehuchte, B. Wermelinger, M. Fraefel, et. al., Biological Conservation. 212:A, 366-375 (2017)

2. L. Lenoi, European Journal of Soil Biology, 38:1, 97-102 (2002)

3. A. E. Lamb, J.G. Ollason, Behavioural Processes, 28:3, 189-198 (1993)

4. N.M. Bugrova, J. I. Reznikova, Mem. zool., 44, 13-19 (1990)

5. W. T. Szczepanski, T. Podkowka, Sylwan, 127:5, 35-44 (1983)

6. E. Belskaya, A. Gilev, E. Belskii, Environmental Science and Pollution Research, 24:11, 10768-10777 (2017)

7. O. Skaldina, J. Sorvari, Ecological Indicators, 72, 444-451 (2017)

8. O. Skaldina, S. Peräniemi, J. Sorvari, Environmental Pollution, 240, 574-581 (2018)

9. A. V. Gilev, A.V. Mershchiev, D. S. Malyshev, Entomological Review, 95:8, 941-946 (2015)

10. Ch. Catarineu, J.-L. Reyes-López, J. A. Herraiz Cabello, G. G. Barberra European Journal of Entomology, 115, 562-574 (2018)

11. Z. R. Stahlschmidt, D. Johnson, Urban Ecosystems 21, 3 (2018)

12. J. Sorvari, R. A. Elo, S. K. Härkönen, Applied Soil Ecology, 101, 101-106 (2016)

13. G. Berberich, A. Grumpe, M. Berberich, D. Klimetzek, C. Wöhlerb, Ecological Indicators, 61:2, 968-979 (2016)

14. A. A. Zakharov, Entomological Review, 95:8 , 959-971 (2015)

15. S. Blinova, M. Korchagina, A. Radosteva, T. Dobrydina, E3S Web Conf., 41, 02024 (2018)

16. W. Czechowski, A. Radchenko, W .Czechowska, The ants (Hymenoptera, Formicidae) of Poland. Warsaw: Museum and Institute of Zoology, Polish Academy of Sciences (PLUS, Warsaw, 2002)

17. B. Hôlldobler, E. Wilson, The ants (Springer-Verlag, Berlin, 1990)

18. A. A. Zakharov, R. A. Zakharov, Entomological Review, 91:2, 141-151 (2011)

19. S. V .Blinova, Russian Journal of Ecology, 42:6, 525-528 (2011) 